\title{
Middle turbinate osteoma
}

\section{B. Viswanatha}

\begin{abstract}
A 14-year-old female patient presented with six months history of progressive nasal obstruction on the left side associated with ipsilateral facial pain. Radiograph of the nose and paranasal sinuses showed a bony mass arising from the left lateral nasal wall. Under general anesthesia left lateral nasal wall is approached through a modified Lynch incision. A bony mass arising from the ant part of the middle turbinate was removed. Histopathological examination of the resected specimen showed picture of an osteoma. The postoperative course was uneventful.
\end{abstract}

Keywords Osteoma $\cdot$ Turbinate $\cdot$ Nasal

B. Viswanatha $(\square)$

ENT Department,

Victoria Hospital, Bangalore Medical College and Research Institute, Bangalore, India

B. Viswanatha $(\square)$

e-mail: drbviswanatha@yahoo.co.in

\section{Introduction}

Nasal osteomas are the benign tumors of the bone of the nose and paranasal sinuses [1]. Osteomas grow slowly and they are capable of extending to surrounding structures, which may result in severe complications such as orbital involvement or intracranial invasion $[1,2]$. It is the most common benign lesion of the paranasal sinuses and it is less common in the nasal cavity [2]. Osteomas occur commonly in frontal sinus, followed by the ethmoid and maxillary sinus, very rarely in the sphenoid sinus [3].

Review of literature showed only two reported cases of middle turbinate osteoma [1, 4]. A rare case of middle turbinate osteoma is presented along with the review of literature.

\section{Case report}

A 14-year-old female patient presented with six months history of progressive nasal obstruction on the left side associated with ipsilateral facial pain. Past medical history was unremarkable. There was no history of nasal trauma or nasal surgery. Intarnasal examination showed a swelling at the anterior part of the left middle turbinate, which was bony hard in consistency.

Radiograph of the nose and paranasal sinuses showed a bony mass arising from the left lateral nasal wall (Fig. 1). Our patient could not afford a CT scan. The results of other routine laboratory and physical examinations were normal.

Under general anesthesia left lateral nasal wall is approached through a modified Lynch incision. A bony mass arising from the ant part of the middle turbinate was removed. Histopathological examination of the resected specimen showed picture of an osteoma (Fig. 2). The postoperative course was uneventful. Following surgery the patient was free from nasal obstruction and ipsilateral facial pain. 


\section{Discussion}

Nasal osteomas are benign tumors that may occur at any age, but it usually occurs in second to fourth decade. It

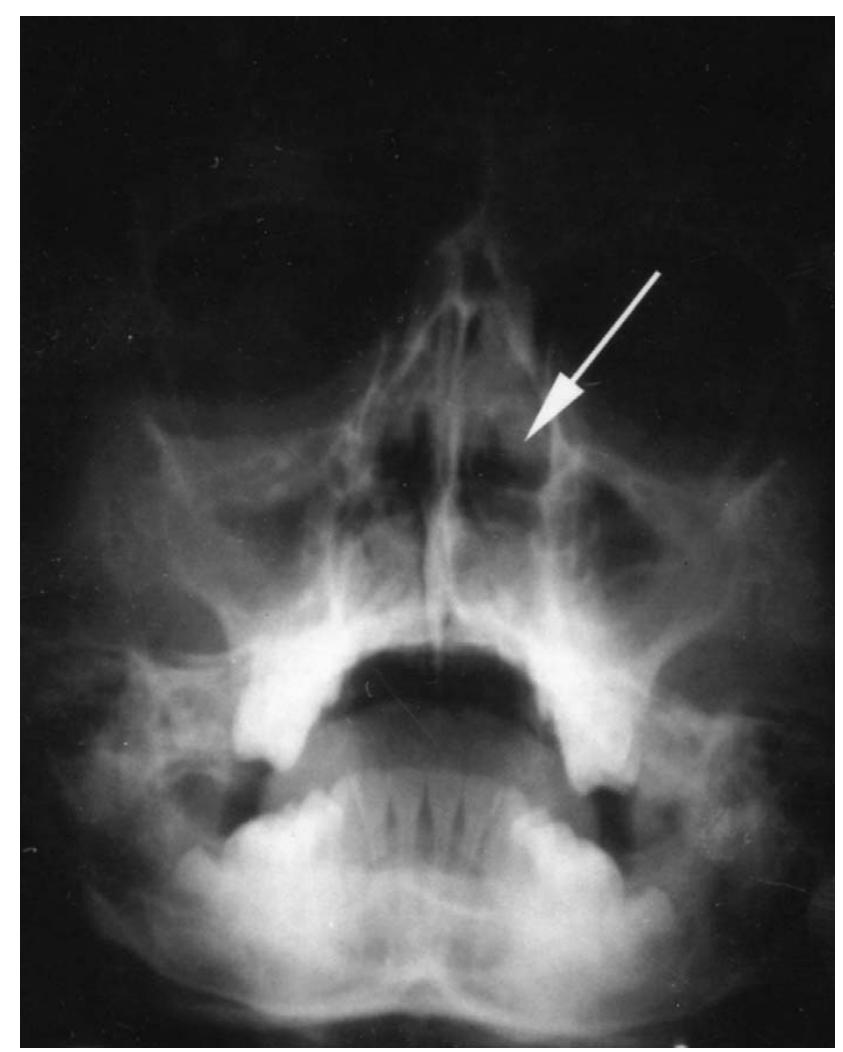

Fig. 1 X-ray paranasal sinuses showing a bony mass (arrow) arising from the lateral wall of the nose on the left side

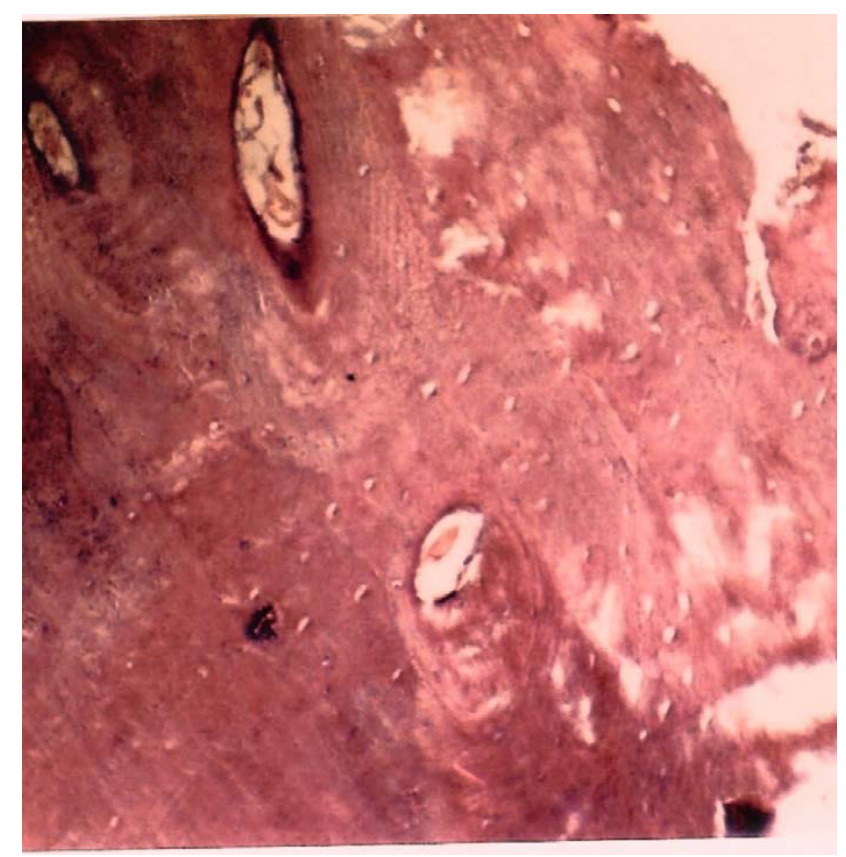

Fig. 2 Photomicrograph of osteoma showing mature dense lamellar bone and fibro vascular channel (H\&E 10X)
Table 1 Reported cases of osteomas of the turbinate

\begin{tabular}{lcl}
\hline Author & Year & Site \\
\hline $\begin{array}{l}\text { Whittet and } \\
\text { Quiney [4] }\end{array}$ & 1988 & Middle turbinate \\
$\begin{array}{l}\text { Chao-jung Lin } \\
\text { et al [1] }\end{array}$ & 2003 & Middle turbinate \\
$\begin{array}{l}\text { Massimo } \\
\text { Mesolella et al [2] }\end{array}$ & 2005 & Inferior turbinate \\
$\begin{array}{l}\text { Ishimaru T [6] } \\
\text { B. Viswanatha } \\
\text { (present study) }\end{array}$ & 2005 & Superior turbinate \\
\hline
\end{tabular}

has male preponderance [5]. Osteomas frequently occurs in frontal sinus $(52 \%)$ followed by ethmoid $(22 \%)$, and maxillary sinus, and in the nose $(0.6 \%)$.Nasal turbinate osteomas are very rare [5]. Only two cases of middle turbinate osteoma, one case of inferior turbinate osteoma and one case of superior turbinate osteoma are reported in the literature (Table 1) $[1,2,4,6]$.

These neoplasm are well localized and discreete. They remain silent for many years, and shows little tendency to recur after excision unless incompletely excised [2].

The majority of osteomas is asymptomatic at an early stage and usually found on routine radiological examination [1]. Delay in diagnosis has been attributed to the fact that these lesions are asymptomatic when they are small [2].

The clinical signs symptoms and complications depend on the location, size and growth direction of the lesion. Thus an anterior extension may lead to facial deformity; whereas posterior growth may lead to intracranial extension [1]. Continued growth may completely obstruct the sinus ostia or nasal cavity and leads to the development of frontal or fronto ethmoidal mucoceles $[1,2]$.

$\mathrm{CT}$ is an effective method for determining the site and extent of the tumour. MR imaging is another diagnostic tool hat is helpful in differentiating inflammatory lesions from neoplasm $[1,2]$.

Asymptomatic osteomas may not require intervention. Symptomatic osteomas require surgical intervention [2]. Surgical procedure depends on the location and extent of the osteoma and existing complications [1]. Small osteomas can be removed by transnasal approach and lateral rhinotomy is suitable for osteomas involving ethmoidal region [7].

Our patient had relief from nasal obstruction and facial pain after surgery. There was no recurrence during a follow up period of three years.

\section{References}

1. Choao-Jung Lin, Yaoh-ShiangLin, Bor-Hwang Kang (2003) Middle turbinate osteoma present- 
ing with ipsilateral facial pain,epiphora and nasal obstruction.Otolaryngol Head and Neck 128: 282-283

2. Massimo M, Vieri G, Domenico T (2005) Infrior turbinate osteoma:A rare cause of nasal obstruction. Otolaryngol Head and Neck 133:989-991

3. Mikaelian DO, Lewis WJ, Behringer WH (1976) Primary osteoma of the sphenoid sinus.Laryngoscope 86 : 728-733
4. Whittet HB, Quiney RE (1988) Middle turbinate osteoma:an unusual cause of nasal obstruction. J Laryngol Otol 102:359-361

5. Handousa AS (1940) Nasal osteomata. J Laryngol Otol 55:197-224

6. Ishimaru T (2005) Superior turbinate osteoma: a case report. Ausis Nasus Larynx 32(3):291-293

7. Atallah N, Jay MM (1981) Osteoma of the paranasal sinuses. J Laryngol Otol 95:291-304 